\section{O processo de implantação do Serviço de Atendimento Móvel de Urgência no Brasil: estratégias de ação e dimensões estruturais}

\author{
Implementation of the Mobile Emergency Medical \\ Service in Brazil: action strategies and \\ structural dimension
}

\section{El proceso de implantación del Servicio de Atención Móvil de Urgencia en Brasil: estrategias de acción y dimensiones estructurales}

\section{Resumo}

O Serviço de Atendimento Móvel de Urgência (SAMU) foi o primeiro componente da Politica Nacional de Atenção às Urgências implantado no país no começo dos anos 2000. O artigo analisou o processo de implantação da urgência pré-hospitalar móvel no Brasil. Os métodos incluíram análise documental, entrevistas com coordenadores estaduais de urgência e um painel de especialistas. Utilizou-se o referencial teórico da análise da conduta estratégica da Teoria da Estruturação de Giddens. Os resultados evidenciaram uma implantação do SAMU desigual entre estados e regiões, identificando seis padrões de implantação considerando-se a capacidade dos estados de expandir a cobertura populacional e de regionalizar. As dificuldades estruturais incluíram a fixação de médicos, centrais de regulação mal equipadas e escassez de ambulâncias. Norte e Nordeste foram as regiões mais atingidas. O SAMU está configurado como estratégia estruturante da rede de urgências, mas seu desempenho sofreu o impacto da pouca participação da atenção primária na rede de urgências e principalmente da falta de leitos hospitalares.

Emergências; Ambulâncias, Políticas, Planejamento e Administração em Saúde
Gisele O’Dwyer 1

Mariana Teixeira Konder 1

Luciano Pereira Reciputti 1

Cesar Macedo 2

Monica Guimarães Macau Lopes 3

doi: 10.1590/0102-311X00043716

\section{Correspondência}

G. O'Dwyer

Departamento de Administração e Planejamento em Saúde, Escola Nacional de Saúde Pública Sergio Arouca, Fundação Oswaldo Cruz.

Rua Leopoldo Bulhões 1480, Rio de Janeiro, RJ 21041-210, Brasil.

odwyer@ensp.fiocruz.br

1 Escola Nacional de Saúde Pública Sergio Arouca, Fundação Oswaldo Cruz, Rio de Janeiro, Brasil.

2 Hospital do Coração, São Paulo, Brasil.

3 Secretaria de Atenção à Saúde, Ministério da Saúde, Brasília, Brasil. 


\section{Introdução}

A atenção às urgências tornou-se prioridade federal no Brasil em consequência do enorme desgaste vigente nos serviços hospitalares de urgência. No ano 2000, profissionais médicos pertencentes à Rede Brasileira de Cooperação em Emergência (RBCE) denunciaram em um congresso a falta de regulação sobre o tema e, a partir de então, um grupo de trabalho estabeleceu junto ao Ministério da Saúde as bases conceituais que instituíram a Política Nacional de Atenção às Urgências (PNAU). Identificam-se três etapas na implantação da política de urgência no Brasil: até 2003, produção das principais normas que instituem a política; de 2003 a 2008 predomina a implantação do Serviço de Atendimento Móvel de Urgência (SAMU); e de 2008 a 2009 predomina a implantação das Unidade de Pronto Atendimento (UPA) 1. A partir de 2011 foi instituída a Rede de Urgência e Emergência (RUE), priorizando-se a integração entre os componentes da atenção às urgências e o investimento menos fragmentado em componentes individuais da política 2.

São integrantes assistenciais da RUE: os componentes pré-hospitalares (atenção básica, salas de estabilização, SAMU-192 e UPA), o componente hospitalar e a atenção domiciliar 2.

O SAMU-192 3 (doravante referido apenas como SAMU) foi escolhido como o modelo de atendimento móvel de urgência a ser implantado no país, portanto, representa o componente móvel de urgência normativamente instituído.

É um serviço de socorro pré-hospitalar móvel, em que o usuário solicita atendimento por intermédio do acesso telefônico gratuito pelo número 192. Tem um componente regulador (Central Médica de Regulação) e um componente assistencial (equipe das ambulâncias). Na central de regulação, todas as etapas dos atendimentos devem ser registradas no computador e gravadas. As chamadas são atendidas por telefonista que identifica o paciente e o local da chamada, e transfere o atendimento para o regulador médico que pode orientar o paciente por telefone ou acionar a equipe assistencial. Para a assistência ao paciente as ambulâncias são de dois tipos: Unidades de Suporte Básico (USB), com técnico de enfermagem na equipe de saúde; e Unidade de Suporte Avançado (USA), ambulância com mais recursos tecnológicos e com médico e enfermeiro na equipe. As ambulâncias podem ficar baseadas na própria central de regulação ou em bases descentralizadas, nos casos de SAMUs metropolitanos ou regionalizados. Compõem a frota em função de necessidades regionais as motolâncias, ambulanchas ou embarcações e o aeromédico, composto por helicóptero ou avião. O SAMU potencializa e organiza o acesso aos serviços de urgência hospitalar e ao leito hospitalar, tornando-se uma nova porta de entrada no sistema, capaz de salvar vidas 4,5 .

Recentes no país, alguns estudos contextualizam o SAMU 5,6,7,8,9,10,11,12. A literatura internacional 13,14,15,16, assim como a nacional 1,5,11, apontam bons resultados da atenção pré-hospitalar. Os estudos locais demonstram que as demandas são complexas e que a insuficiência da rede de atenção básica e hospitalar 6,8, a fragilidade dos acordos 6,10, a instabilidade de fixação de médicos e capacitação 6,7, as deficiências estruturais, além do acesso não equitativo 5 podem não ser restritos a estes estudos.

Este artigo tem por objetivo analisar o processo de implantação da urgência pré-hospitalar móvel no Brasil, identificando: as regras e recursos que facilitaram a implantação; os elementos dificultadores e facilitadores neste processo; a influência dos agentes dos diferentes entes federativos na implantação destes serviços; a proposta de expansão dos SAMUs.

\section{Metodologia}

O trabalho envolveu análise da legislação, de outros documentos e de sites oficiais dos municípios, estados e federação, entrevistas com atores-chave e um painel de especialistas.

Elegeram-se os Coordenadores Estaduais de Urgência como atores a serem entrevistados pela relevância que estes gestores têm para a assistência integral às urgências, para a negociação de pactos e metas e cooperação entre entes federativos. Foram convidados os 27 coordenadores estaduais do país; 24 aceitaram participar. As entrevistas realizadas com os coordenadores duraram entre 60 e 100 minutos, baseando-se em um roteiro semiestruturado, e ocorreram em 2013 e 2014. Para este estudo, analisaram-se questões relativas a: antecedentes e trajetória da política; atores envolvidos na implantação; processo de expansão; avanços, limites e dificuldades de implantação; e capacidade de 
coordenação estadual. O painel de especialistas tratou de forma coletiva os temas das entrevistas. Realizou-se em dois dias (16 horas) no final de 2013 e contou com os 24 coordenadores estaduais de urgência, o Coordenador Geral de Urgência e Emergência do Ministério da Saúde, representando o nível central, e três integrantes da RBCE, protagonista na formulação da política.

Utilizou-se o referencial teórico da análise da conduta estratégica da Teoria da Estruturação de Giddens 17, em que as práticas sociais podem ser entendidas como procedimentos, métodos ou técnicas hábeis executadas pelos agentes sociais, utilizando-se regras e recursos estruturais. As regras têm um aspecto normativo dos direitos e obrigações e um aspecto semântico, mais qualitativo e processual, associado ao desempenho. Os recursos são autoritativos, próprios da relação entre pessoas, ou alocativos, relativos às capacidades materiais. As dimensões estruturais são a base de poder (facilitadoras ou restritivas) as quais o agente tem acesso e que manipula para influenciar as interações sociais 17 .

O plano de análise das entrevistas e painel visou a identificar as circunstâncias estruturais disponíveis para a ação dos gestores e estratégias que diferenciaram os estados, caracterizando a implantação do SAMU no país.

Este projeto foi aprovado pelo Comitê de Ética em Pesquisa da Escola Nacional de Saúde Pública Sergio Arouca, Fundação Oswaldo Cruz (CAAE no 0209.0.031.000-11).

\section{Resultados/Discussão}

As portarias referentes à formulação da política de urgência foram analisadas. Pesquisaram-se os sites oficiais dos estados e capitais, com resultado frustro, apenas dois estados tinham site com informações sobre o SAMU; relatório disponibilizado pelo Ministério da Saúde que informava a esfera responsável pela gestão dos SAMUs; e a Sala de Apoio à Gestão Estratégica da página do Ministério da Saúde.

Seis estados disponibilizaram relatórios com indicadores descritivos do SAMU como tipo de atendimento, destino e tempo-resposta. Todavia, essas informações não foram suficientes para produzir um panorama consolidado dos atendimentos.

Com base nas entrevistas e no conteúdo discutido no painel foram identificados os subtemas apresentados a seguir.

\section{Antecedentes da atenção pré-hospitalar móvel}

Antes da regulamentação federal, a forma mais organizada de atendimento móvel era realizada pela Corporação dos Bombeiros que, em muitos estados, representava a única alternativa de atenção pré-hospitalar, restrita à via pública. Poucas corporações contavam com profissionais de saúde nesse atendimento, como era o caso do Rio de Janeiro, com médicos na regulação e atendimento ${ }^{5}$. O Sistema Integrado de Atendimento ao Trauma e Emergência (SIATE) também integravam bombeiros e secretaria estadual de saúde, envolvendo médicos, como em Curitiba (Paraná). O caso do Município de São Paulo é emblemático, pois contava com um serviço que fazia atendimento clínico domiciliar conhecido pela sigla APH, e também com o então já denominado SAMU (baseados no modelo francês), em que a secretaria de saúde formava uma parceria com o Corpo de Bombeiros para o atendimento pré-hospitalar com médicos, sendo por isto conhecido como SAMU-193. No interior de São Paulo também existiam experiências de SAMU, como em Ribeirão Preto.

Outra forma tradicional de atendimento móvel, encontrada principalmente nas regiões Norte e Nordeste, eram as chamadas ambulâncias brancas. Tripuladas apenas por condutores, sem profissionais de saúde ou qualquer dispositivo de regulação, realizavam atividades de transporte sanitário, levando pacientes do domić́lio para hospitais. Destaca-se que esse tipo de atendimento era demandado espontaneamente pelos cidadãos e fortemente subdimensionado. Frequentemente, no interior, o acesso a essas ambulâncias brancas era condicionado por ingerências políticas. No Nordeste, exceções a essa realidade foram identificadas em três capitais, onde havia serviço de atenção pré-hospitalar móvel estruturado, os SOS-Emergência Fortaleza (Ceará), Recife (Pernambuco) e Teresina (Piauí).

Até então não havia investimento federal e os estados, via secretaria de saúde ou bombeiros, assumiam a iniciativa de prestar esse atendimento. 


\section{Implantação e expansão do SAMU}

Os primeiros SAMUs inaugurados nas capitais do Brasil foram o de São Paulo em 1989, Belém (Pará) em 1994 e Porto Alegre (Rio Grande do Sul) em 1995. No período de 2000 a 2002 foram inaugurados os SAMUs Natal (Rio Grande do Norte) e Recife. Esses SAMUs, inaugurados antes da primeira regulamentação federal editada em 2003 4, retratam a iniciativa de gestores que pertenciam à RBCE e implementavam soluções locais. Entre 2003 e 2004 foram inaugurados cinco SAMUs. No período 2005-2006 houve uma franca expansão de SAMUs metropolitanos, com 14 inaugurados, atingindo uma cobertura populacional de 35\%. Depois de 2006, mais três capitais inauguraram seus SAMUs. Durante esses anos, outros SAMUs metropolitanos foram inaugurados fora das capitais, com destaque para Campinas e Ribeirão Preto, inaugurados ainda em 1996.

O impulso da implantação dos SAMUs a partir de 2003 é explicado pela existência de uma norma que determinava padrões de construção, alocação de equipamentos e recursos humanos, com forte indução financeira, já que havia responsabilidade de financiamento federal e custeio de 50\% por este ente federativo, alcançando em 2004 a cobertura de 7,8\%. Em 2008, o SAMU já abrangia todas as capitais com cobertura de $52.9 \%$ da população do país 1 . O padrão de implantação dos SAMUs privilegiou inicialmente as capitais, tendência observada até 2006. A partir de 2008, predominaram os SAMUs regionais 1 .

Depois de 2010, houve desaceleração do incremento da cobertura populacional, atingindo em 2010, 64,47\%; em 2013, 72,74\%; e em 2015, 75,92\%. Destaca-se que em 2010 quatro estados tinham coberturas menores que $40 \%$ e cinco apresentavam cobertura menor que 50\%. Em 2013, apenas três estados persistiam com cobertura menor que 50\%. Em 2015, seis estados e o Distrito Federal apresentaram 100\% de cobertura e dois permaneciam com cobertura menor que 50\% (Figura 1).

A implantação do SAMU ainda é bastante desigual entre estados e regiões. A Região Sul apresenta uma cobertura significativa, maior que $80 \%$, e simétrica entre os estados. A Região Norte, apesar de contar com dois estados com cobertura de $100 \%$ da população, engloba os dois únicos com cobertura menor que 50\%. Alguns estados registraram aumento expressivo (> 10\%) de cobertura no período 2010-2015: Paraná, São Paulo, Mato Grosso, Mato Grosso do Sul, Pará, Roraima, Bahia, Pernambuco, Rio Grande do Norte e Piauí (Figura 1). Essa desigualdade de implantação do SAMU no país demonstra que o nível federal induz financeiramente, mas são os gestores estaduais e municipais que elegem a prioridade. Aponta também a importância dos gestores estaduais na regionalização.

"Com a regionalização, em dois anos passamos de 8 para 45 municípios cobertos" (E13).

Nesses poucos anos foram implantados 188 SAMUs no país, sendo 111 regionalizados, indicando que o processo de regionalização tem sido bem-sucedido. Tendo como referência a cobertura populacional e a capacidade de regionalizar dos estados, foram identificados seis padrões de implantação de SAMU no país (Tabela 1). Os estados que compõem os padrões 1, 2 e 3 alcançaram cobertura entre $80 \%$ e $100 \%$, um bom resultado.

Independentemente da capacidade de implantação de cada estado, de forma unânime, o SAMU foi considerado imprescindível para a conformação da rede de urgência e para a diminuição da morbimortalidade, especialmente por causas externas e cardiovasculares.

"O SAMU cumpre seu papel. Agora atende-se quem morria em casa" (E21).

"Todo mundo quer o SAMU no seu município. Do gestor até a população" (E12).

Segundo o gestor federal, a expansão prevista de cobertura do SAMU para 2019 é de $83 \%$. Observou-se que para o processo de implantação descrito houve confluência de disponibilidade de recursos estruturais e protagonismo dos agentes municipais e estaduais.

\section{A regulação no SAMU e as condições estruturais para o atendimento}

A regulação no SAMU é aspecto crítico para o seu desempenho. $\mathrm{O}$ ato de regular é prerrogativa do médico, altamente dependente das condições estruturais das Centrais de Regulação e do seu conhecimento e capacidade de mobilização dos recursos e regras cabíveis. Um estudo sobre a regulação no Rio de Janeiro indicou que a ação do regulador de enviar ambulância ocorre com base em dois critérios básicos: a existência do recurso e o reconhecimento da sua necessidade ${ }^{10}$. $\mathrm{O}$ aspecto normativo da regulação está bem descrito nas portarias. Uma questão crucial é a concepção divergente 
Figura 1

Cobertura do Serviço de Atendimento Móvel de Urgência (SAMU), por Unidade Federativa. Brasil, anos 2010 e 2015.

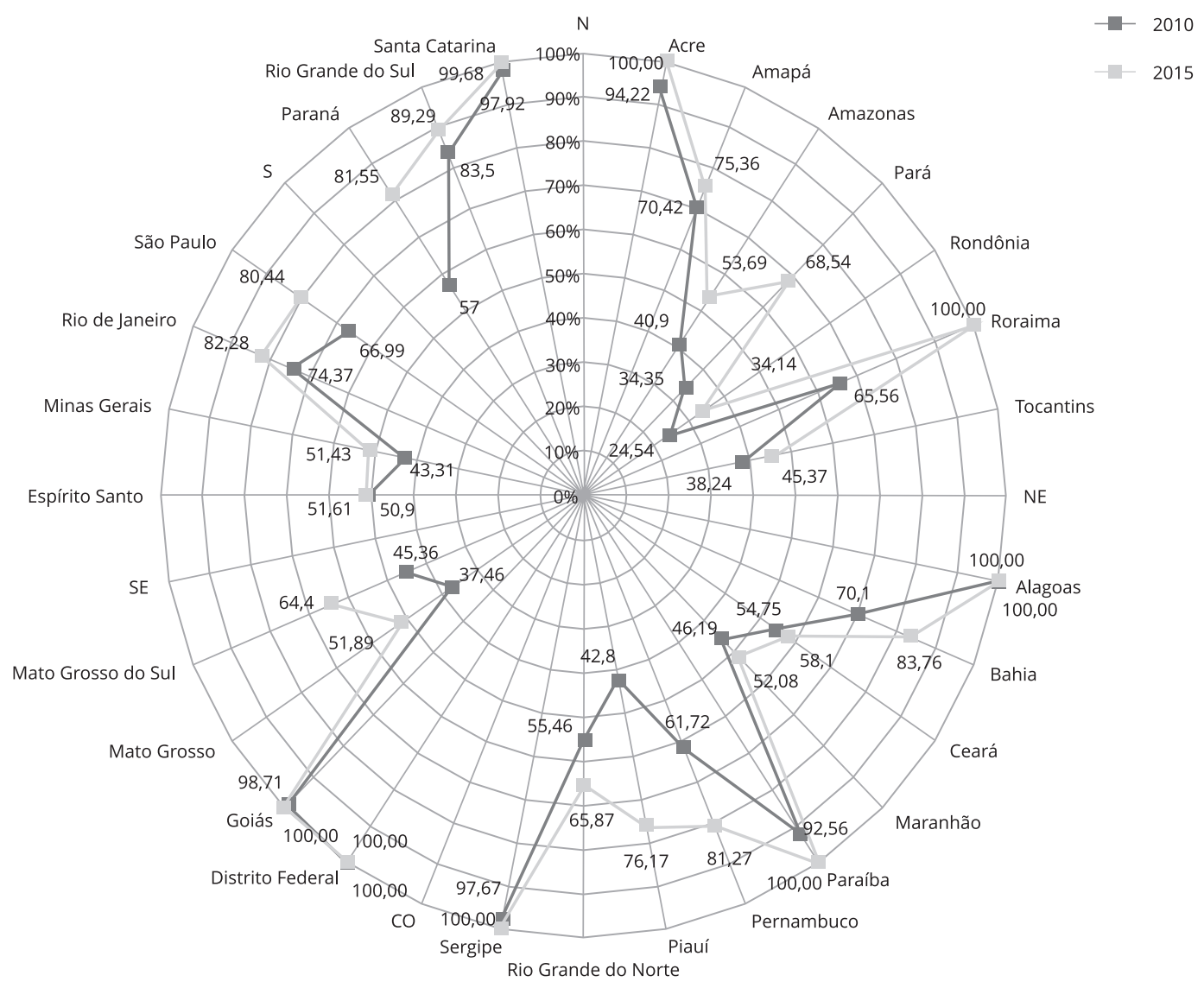

Fonte: dados do Ministério da Saúde, elaboração própria.

de urgência entre médico e paciente. As portarias são inovadoras ao reconhecerem que as concepções de médico e usuário são diversas, porém, legítimas. Entretanto, observaram-se posturas antagônicas sobre o conceito de "urgência": reguladores que negam ambulâncias quando não identificam risco iminente de morte; demandas da população para transporte pelas ambulâncias do SAMU na ausência de urgência.

"Regulação da negação do atendimento. Mentem dizendo não ter ambulância. População descobre que tem ambulância, ameaça o regulador" (E18).

"Paciente liga dizendo que é dor de barriga. Não é atendido, na segunda vez diz que foi facada. Quando a ambulância chega, é gastroenterite” (E9).

A procura por atendimento a uma situação de baixa gravidade ou que não corresponda à finalidade dos serviços móveis de urgência é um fenômeno internacional e previsível em sistemas de saúde deficientemente estruturados. Segundo os dados disponibilizados, 40 \% das ligações são trotes, 50\% dos atendimentos requerem somente orientação, e apenas $10 \%$ das ligações exigem envio de ambulância.

Os entrevistados identificaram influências culturais para as demandas da população para o transporte pelas ambulâncias do SAMU na ausência de urgência. Antes do SAMU, as ambulâncias tradicionalmente faziam transporte de pacientes sem necessidade de regulação médica. Era um processo automático, bastava pedir, e muitas vezes altamente influenciado por interesses políticos.

"Demanda social, transporte de pacientes supera a de urgência" (E6). 
Tabela 1

Tipologias de implantação do Serviço de Atendimento Móvel de Urgência (SAMU) considerando a capacidade de expansão e regionalização. Brasil, 2015.

\begin{tabular}{|c|c|c|}
\hline Tipologia & Características & Área de abrangência \\
\hline Padrão 1 & $\begin{array}{l}\text { SAMUs estaduais que incluem a capital com cobertura pelo SAMU de } \\
\qquad 100 \% \text { da população }\end{array}$ & $\begin{array}{c}4 \text { estados (Acre, Roraima, Alagoas e Sergipe) e o } \\
\text { Distrito Federal }\end{array}$ \\
\hline Padrão 2 & $\begin{array}{l}\text { SAMUs das capitais regionalizados, com cobertura maior que } 80 \% \text { (sendo } \\
\qquad 2 \text { com } 100 \% \text { ) }\end{array}$ & $\begin{array}{c}6 \text { estados (Paraná, Santa Catarina, Goiás, Bahia, } \\
\text { Paraíba e Pernambuco) }\end{array}$ \\
\hline Padrão 3 * & $\begin{array}{l}\text { SAMUs cuja capital persiste com SAMU municipal, mas regionalizados no } \\
\text { interior alcançando cobertura de SAMU acima de } 80 \%\end{array}$ & $\begin{array}{l}3 \text { estados (Rio de Janeiro, São Paulo e Rio Grande } \\
\text { do Sul) }\end{array}$ \\
\hline Padrão 4 & $\begin{array}{l}\text { SAMUs regionalizados na capital, porém com coberturas no estado } \\
\text { inferiores a } 80 \%\end{array}$ & $\begin{array}{c}5 \text { estados (Amapá, Pará, Maranhão, Piauí e Minas } \\
\text { Gerais) }\end{array}$ \\
\hline Padrão 5 & $\begin{array}{l}\text { SAMUs estaduais na capital, porém com coberturas baixas por } \\
\text { dificuldade de regionalizar no interior }\end{array}$ & 2 estados (Espírito Santo e Mato Grosso) \\
\hline Padrão 6 & $\begin{array}{l}\text { SAMUs municipais na capital, porém com coberturas baixas por } \\
\text { dificuldade de regionalizar no interior }\end{array}$ & $\begin{array}{l}6 \text { estados (Amazonas, Rondônia, Tocantins, Ceará, } \\
\text { Rio Grande do Norte e Mato Grosso do Sul) }\end{array}$ \\
\hline
\end{tabular}

* O fato de essas capitais permanecerem com SAMUs municipais não é um retrocesso, mas uma acomodação para capitais muito populosas.

Fonte: dados fornecidos pelo Ministério da Saúde, elaboração própria.

Ainda acontece de o gestor local tentar definir a utilização da ambulância, produzindo um constrangimento para a autoridade do regulador.

Outra forma de representação da divergência de concepção de urgência é o trote, problema recorrente nas centrais do SAMU.

"Equívocos que favorecem o trote como o regulador dizer que só manda ambulância se o paciente estiver inconsciente. A população aprende e liga dizendo que o paciente está desmaiado. A ambulância chega, ele está com a maleta pronta para ir pro hospital. É urgência social" (E10).

As estratégias usadas para combatê-lo têm sido educativas, como o projeto Samuzinho de visitas às escolas, com bons resultados, além de propagandas em lugares públicos.

"Comercial no horário nobre reduziu os trotões de 40 a 60\% pra 10\%" (E10).

Outra dificuldade para a condução da regulação identificada foi a insuficiente capacitação do médico regulador. Foram apontados os seguintes constrangimentos: capacitação pontual; ausência de política de educação permanente; formação centrada nos aspectos técnicos do atendimento, insuficiente para regular sob uma compreensão ampliada de urgência; rotatividade dos médicos exigindo elevado investimento; e baixa adesão dos médicos, mesmo com ambiente favorável à capacitação.

"Não tem adesão de médico por falta de política, salário, capacitação e apoio técnico" (E16).

Apesar de insuficiente, 11 estados capacitavam regularmente e de forma apropriada seus profissionais, referindo bons resultados.

Sobre a existência de recursos para a regulação, identificaram-se limitações importantes. As centrais de regulação tinham como problemas estruturais os sistemas de informação e de comunicação. O Ministério da Saúde contava com um sistema informatizado a ser ofertado para todas as centrais de regulação.

"Não temos estrutura tecnológica compatível com o padrão. Não estamos conseguindo gravar os chamados" (E6).

"Sede do SAMU muito precária. Telefone fica sem linha, telefone do SAMU era um orelhão que fica em frente. Está reestruturando” (E5).

Em quatro estados os SAMUs não são informatizados ou não gravam seus atendimentos, condições mínimas exigidas em Portaria. Um na Região Norte e três na Região Nordeste.

"Sistema de informação do ministério é capenga. Dois anos pra trocar o sistema, sem contrato de manutenção. Mais de um ano que é tudo na mão" (E14).

A telefonia depende dos recursos locais. As dificuldades de comunicação por celular ou com o número 192 aconteceram nas regiões Norte, Nordeste e Centro-oeste. 
"As informações são por celular, sem comunicação em vários pontos. Rádio também funciona com dificuldade. Tem dificuldade de comunicação na região metropolitana, imagina o resto" (E4).

"Celular não pega no interior, tem que ser rádio, que não cobre 100\%" (E18).

Poucos SAMUs, em especial nas capitais do Sul e Sudeste, eram excepcionalmente bem estruturados e contavam com softwares próprios e autofinanciados, o que potencializa a capacidade de desempenho e monitoramento.

"Central toda televisionada, vê as ambulâncias, médicos gerenciam os tempos" (E21).

"Sistema georreferenciado vê o movimento da frota. Controla o perímetro de deslocamento da ambulância, a velocidade" (E24).

Outra dificuldade estrutural relevante foi a carência de profissionais para o posto de médico na regulação e ambulâncias USA. Localizar a central de regulação na capital foi uma estratégia utilizada para pagar um salário para o médico regulador menos inflacionado do que no interior.

A alocação de médicos no SAMU enfrentou duas restrições principais. Uma diz respeito à capacidade do gestor de arcar financeiramente com esse profissional.

"Os municípios menores não têm condições de custear o médico na USA. Eu não vou ter USA nessa cidade" (E3).

A outra se refere à escassez desse profissional para ocupar postos de trabalho disponíveis.

"As UPA, SAMU, policlinicas e hospitais municipais concorrem pelo médico" (E11).

Atualmente, existem 2,09 médicos por mil habitantes no Brasil, número considerado insuficiente. Regionalmente, Norte e Nordeste têm menos médicos do que a média nacional: 1,09 e 1,30 por mil habitantes, respectivamente ${ }^{18}$. Além do déficit numérico, há distribuição regional desigual e uma circulação intensa de médicos em todas as regiões ${ }^{19}$. No interior, a participação dos profissionais não exclusivos aos municípios é extremamente relevante, principalmente para aqueles de menor porte. O mercado de trabalho regional não é capaz de reter esses médicos e é graças a essa circulação que ocorre a ampliação de acesso em regiões desprovidas de profissionais fixos ${ }^{19}$. Entretanto, esse padrão compromete o desempenho do profissional, principalmente na regulação, em que a autoridade sanitária é inerente à atuação do médico.

A dificuldade de fixação do médico foi recorrente especialmente nas regiões Norte, Nordeste e Centro-oeste, onde 11 estados afirmaram ter vagas não preenchidas nas ambulâncias USA. Nas regiões Sul e Sudeste, um estado declarou dificuldade de fixar médicos.

"Mesmo no SAMU, considerado 'muito bem estruturado', há falta de médicos nas ambulâncias" (E15).

Outra questão são os vínculos trabalhistas variados e precários que afetam mais essa categoria. Mesmo onde o conjunto de profissionais era concursado, os médicos tinham outros vínculos.

"Médicos muito novos, inexperientes, cooperativados, muita rotatividade" (E13).

Quanto à estrutura de ambulâncias do SAMU, originalmente a legislação recomendava a constituição de frota na proporção de 1 USB e 1 USA para cada 150 mil e 450 mil habitantes, respectivamente. Esse critério se mostrou insuficiente para o alcance de tempos-resposta satisfatórios (intervalo entre acionamento e chegada da ambulância à cena), principal indicador de qualidade do SAMU. Condições geográficas e de mobilidade, além de distribuição e densidade populacional, passaram a ser consideradas como critérios mais úteis para alocação de ambulâncias.

Analisando os sete estados com 100\% de cobertura populacional, confirma-se que nestes estados o critério populacional de 1 USB para 150 mil pessoas foi superado. Há 3 a 4 vezes mais USBs do que o proposto pela legislação. Explica-se esse fato pelo menor custo da USB, ambulância sem médico e enfermeiro. O mesmo não acontece com as USAs. A não adequação da frota de USA interfere com o desempenho do SAMU, já que esta ambulância é tripulada por médico e dispõe de mais recursos.

"Regulador envia USB para poupar USA de forma equivocada. Paciente morre no trajeto" (E3).

Apenas três estados têm 2 a 4 vezes mais USAs do que o indicado nas portarias. A dificuldade de ultrapassar o critério populacional para as USAs pode ser explicada pelo custeio e, igualmente, pela já referida dificuldade de lotar médicos.

Entretanto, é desejável uma evolução do número de USA semelhante à que ocorreu no número de USB, dada a importância deste atendimento para a resolução dos casos graves. Destaca-se a Paraíba que excede em muito o número de ambulâncias dos dois tipos, além de apresentar um número significativo de motolâncias.

Entrevistados de sete estados, distribuídos entre todas as regiões, com exceção da Região Sul, referiram escassez de ambulâncias pelo sucateamento e não reposição. 
"O financiamento do ministério é que a cada 4 anos você renove a frota. A frota fica ruim muito antes disso" (E14).

Sobre a manutenção das mesmas, o problema é mais significativo no Norte, onde em um estado só há oficina habilitada na capital, gerando uma espera média de dois meses.

A Tabela 2 ilustra a distribuição de ambulâncias por estado e outras formas de transporte previstas na política em 2015. Os diversos tipos de transporte visam a atender o paciente com o melhor recurso no menor tempo possível.

"Existem muitos municípios da nossa região que o acesso fluvial é muito maior que o terrestre, só que o tempo-resposta é muito grande, eu saio de lancha de uma região, chego num município aonde tem aeroporto, e dali ele é transferido para a capital por via aérea" (E3).

Tabela 2

Quantidade e tipo de veículo do Serviço de Atendimento Móvel de Urgência (SAMU), por Unidade Federativa (UF). Brasil, 2015.

\begin{tabular}{|c|c|c|c|c|c|}
\hline UF & USA & USB & Motolância & Ambulancha & Aeromédico \\
\hline Acre & 3 & 26 & 2 & 0 & 1 \\
\hline Amapá & 4 & 5 & 0 & 2 & 0 \\
\hline Amazonas & 7 & 25 & 5 & 3 & 0 \\
\hline Pará & 9 & 78 & 4 & 0 & 0 \\
\hline Rondônia & 2 & 9 & 0 & 2 & 1 \\
\hline Roraima & 1 & 17 & 2 & 0 & 0 \\
\hline Tocantins & 4 & 13 & 0 & 0 & 0 \\
\hline Total (Região Norte) & 30 & 173 & 13 & 7 & 2 \\
\hline Alagoas & 8 & 47 & 3 & 0 & 0 \\
\hline Bahia & 54 & 266 & 34 & 1 & 0 \\
\hline Ceará & 15 & 60 & 6 & 0 & 0 \\
\hline Maranhão & 24 & 74 & 9 & 0 & 0 \\
\hline Paraíba & 40 & 123 & 17 & 0 & 0 \\
\hline Pernambuco & 23 & 146 & 16 & 1 & 2 \\
\hline Piauí & 15 & 81 & 3 & 0 & 0 \\
\hline Rio Grande do Norte & 12 & 38 & 0 & 0 & 1 \\
\hline Sergipe & 16 & 42 & 3 & 0 & 0 \\
\hline Total (Região Nordeste) & 207 & 877 & 91 & 2 & 3 \\
\hline Distrito Federal & 7 & 30 & 22 & 0 & 0 \\
\hline Goiás & 30 & 116 & 24 & 0 & 0 \\
\hline Mato Grosso & 8 & 29 & 3 & 0 & 0 \\
\hline Mato Grosso do Sul & 6 & 26 & 1 & 0 & 0 \\
\hline Total (Região Centro-oeste) & 51 & 201 & 50 & 0 & 0 \\
\hline Espírito Santo & 7 & 17 & 4 & 0 & 0 \\
\hline Minas Gerais & 40 & 162 & 1 & 0 & 0 \\
\hline Rio de Janeiro & 45 & 134 & 4 & 1 & 0 \\
\hline São Paulo & 96 & 481 & 58 & 0 & 0 \\
\hline Total (Região Sudeste) & 188 & 794 & 67 & 1 & 0 \\
\hline Paraná & 38 & 132 & 1 & 0 & 1 \\
\hline Santa Catarina & 24 & 104 & 0 & 0 & 1 \\
\hline Rio Grande do Sul & 36 & 182 & 2 & 0 & 0 \\
\hline Total (Região Sul) & 98 & 418 & 3 & 0 & 2 \\
\hline Total (Brasil) & 574 & 2.463 & 224 & 10 & 7 \\
\hline
\end{tabular}

USA: Unidade de Suporte Avançado; USB: Unidade de Suporte Básico.

Fonte: Sala de Apoio à Gestão Estratégica (http://sage.saude.gov.br), elaboração própria. 
As embarcações estão localizadas na Região Norte, como esperado pela configuração geográfica destes estados, com exceção da Bahia e do Rio de Janeiro. Os aeromédicos estão igualmente distribuídos entre as regiões Norte, Nordeste e Sul e são vitais para as grandes distâncias 16. Estados que dependem do serviço aéreo para o transporte de seus pacientes, arcam com esse custo.

"Tem helicóptero pra curta distância pago pelo estado, piloto, copiloto, médico e enfermeiro também" (E4).

Quanto às motolâncias, predominam nas regiões Nordeste e Norte, com uma enorme concentração na Bahia (especialmente na capital), e em São Paulo (distribuídas entre interior e capital). Essa concentração nos dois estados parece indicar maior capacidade de responder à necessidade de capacitação do condutor (técnico de enfermagem) pela polícia federal, exigência da legislação, difícil de cumprir em muitos estados.

"A gente recebeu 39 motolâncias. Só 3 estão habilitadas. A polícia federal não teve capacidade técnica de capacitar. Devolvemos motolância” (E14).

Ao contrário do que se poderia supor, critérios geográficos e de aglomerados urbanos não estão relacionados à distribuição de motolâncias. Numérica e qualitativamente, critérios geográficos não justificaram a alocação da frota no país.

A regulação médica e o atendimento por ambulâncias no SAMU evidenciaram mais uma vez a profícua relação entre disponibilidade de recursos e atuação responsável dos atores envolvidos.

\section{O SAMU e outros componentes da rede de urgência}

Superados os conflitos surgidos na implantação do SAMU 5 junto aos Bombeiros, atualmente o mais prevalente é que os Bombeiros façam o atendimento a acidentes em via pública e auxílio às urgências psiquiátricas. Essa atuação conjunta já foi indicada como bem-sucedida 9. Eventualmente as duas centrais enviam atendimento à mesma ocorrência, desperdiçando recursos.

A atenção básica tem um papel bem definido na política de atenção às urgências, haja vista a exigência em Portaria de implantação do SAMU em áreas com cobertura pela Estratégia Saúde da Família (ESF) de pelo menos 50\%. A cobertura da ESF, apesar de toda a prioridade que assumiu junto ao Ministério da Saúde, ainda era de 56,37\% em 2013, chegando a 60,65\% em 2015. Independentemente da cobertura local, a interação do SAMU com a atenção básica foi considerada incipiente, embora haja o reconhecimento de que locais com ESF instituída demandem o SAMU de forma mais qualificada. Os questionamentos sobre a atuação da ESF incluíram: negação do atendimento às urgências atribuíveis à ESF; baixa cobertura vigente; desempenho insuficiente em alguns locais; e ausência de médicos em algumas equipes.

"Não entendem seu papel na urgência, com raras exceções" (E13).

"No interior, os municípios são pequenos, tem 100\% de cobertura. Entretanto, médico atende 2 dias na semana" (E6).

Muito mais premente para o SAMU, no entanto, é a sua relação com as referências hospitalares por meio dos serviços de emergência e dos leitos, incluindo os de terapia intensiva. Para a implantação do SAMU, as referências hospitalares são a priori definidas. Entretanto, a oferta de leitos SUS em 2014 era de $315.894,10,5 \%$ menor se comparada a 200520.

A oferta da atual rede hospitalar está envelhecida, composta predominantemente por hospitais gerais, de pequeno a médio porte, que fazem o cuidado do agudo, eletivo e crônico, indistintamente. Os hospitais com menos de 50 leitos compõem 63,7\% do total e os de 50 a 100 leitos $18,5 \%$. Os hospitais de 101 leitos ou mais representavam 17,8\% dos hospitais do país em 2014 21. Essa escassez de leitos hospitalares compromete principalmente hospitais maiores, localizados nas capitais e regiões metropolitanas, principais referências do SAMU. O cenário de escassez produz conflitos e os profissionais das emergências hospitalares nem sempre se sentem comprometidos com acordos de referência acertados entre gestores.

"Hospital com deficiência de equipamentos, superlotado, recebe mal o SAMU" (E13).

Por outro lado, a busca pela referência hospitalar pelo médico regulador do SAMU nem sempre utiliza a mais adequada para o paciente.

"Regulador precisa escolher o melhor para o paciente na rede e não levar pro local mais próximo praticando 'reboqueterapia”' (E3). 
Some-se a isso a fragmentação da implantação da política de urgências, que investiu nos segmentos em momentos diversos 1, sendo o componente hospitalar alvo de investimentos tardiamente. A política para hospitais inclui aumento do número de leitos, habilitação de leitos conveniados, instituição de linhas prioritárias de cuidado e núcleos de monitoramento de leitos, mas o impacto ainda é pequeno.

"O déficit de leitos é grande. Saímos de 70 pra 800, mas não é suficiente" (E19).

"Quadruplicou-se a quantidade de leitos em pouco tempo, se fez contratualização, embora a necessidade seja mais veloz do que a resposta" (E11).

O financiamento segue como um importante restritor para o enfrentamento do problema.

Além da ampliação do número de leitos, esforços são necessários para melhorar sua gestão.

"Não é só ampliar quantidade, tem que melhorar a qualidade do leito, melhorar os processos internos, diminuir a taxa de permanência, aumentar a rotatividade" (E11).

"A gente não faz gestão dos leitos conveniados. Nas parcerias com instituições filantrópicas, eles acreditam que são donos dos leitos. Criam uma cultura de que à noite ninguém interna na UTI, você não tem mecanismos de controlar isso" (E18).

Também a emergência hospitalar, tradicionalmente superlotada nos hospitais de referência, depende de uma integração com o restante do hospital para superar a superlotação 22 .

"Precisa tirar a estrutura hospitalar da zona de conforto" (E19).

"Ninguém discute as enfermarias dentro dos pronto-socorros. Ponto esquecido" (E15).

"Portas de entrada muito desestruturadas" (E9).

Os leitos identificados como mais deficitários são os de terapia intensiva.

"Temos um déficit de 500 leitos de UTI. Vamos ampliar 270 leitos" (E23).

A ampliação desses leitos é dificultada porque o gestor volta a esbarrar na fixação do profissional.

"Temos problemas de intensivistas e de habilitação de leitos de UTI" (E19).

"Déficit de leitos de UTI e o estado tem 3 intensivistas e 18 leitos de UTI" (E1).

Problema recorrente para o acesso do SAMU ao componente hospitalar é a concentração dos grandes hospitais nos centros urbanos. Muitos dos hospitais que atendem o interior são os hospitais de pequeno porte (HPP), que têm sido apontados como inadequados 23 , agravando a escassez de leitos.

"Os HPP são pouco resolutivos e atrapalham no dimensionamento da necessidade de leitos" (E1).

A relação do SAMU com o hospital é permeada por divergências conceituais. Constatou-se que na forma de utilizar a prerrogativa da vaga zero - que impede o hospital de referência de negar atendimento alegando falta de vaga - há concepções equívocas entre os médicos. Alguns entendem que o papel do SAMU é encaminhar o paciente para uma emergência hospitalar, concepção mais próxima da proposição normativa, já outros entendem que a vaga de internação deve ser garantida pelo próprio SAMU, condicionando o encaminhamento do paciente.

"Paciente com traumatismo cranioencefálico, com ferimento à bala precisa ir da ambulância pra cirurgia, precisa de porta de entrada, leito é secundário" (E9).

Essa questão não estaria gerando tantos conflitos, não houvesse a grave restrição de leitos no país 20 .

O foco apresentado foi a escassez do recurso de leito hospitalar, entretanto, a superação do problema depende da atuação mais efetiva dos níveis federal e estadual na atenção hospitalar.

\section{A gestão do SAMU e a interação entre os entes federados}

Privilegiaram-se nesta análise os avanços e limites identificados pelos coordenadores estaduais relacionados às categorias: financiamento; gestão colegiada; articulação regional; informação para o planejamento; e desempenho estadual diferenciado (Tabela 3). Essas categorias foram definidas no questionário e tiveram como fonte os relatos dos gestores, retratando suas iniciativas e estratégias de ação.

O Ministério da Saúde foi o ente deflagrador do processo de implantação do SAMU com base em indução normativa e financeira. A participação financeira prevista dos entes federados era $50 \%$ federal, $25 \%$ estadual e $25 \%$ municipal.

Muitos apontaram o financiamento do nível federal como insuficiente, levando os estados e municípios a optarem por financiar o SAMU.

"Estado tem contrapartida 4 vezes maior que o previsto" (E6). 


\section{Tabela 3}

Características da gestão estadual, avanços e limites identificados.

\begin{tabular}{|c|c|c|}
\hline Categoria & Avanços & Limites/Desafios \\
\hline Financiamento & 9 estados investiam mais do que o previsto. & $\begin{array}{c}2 \text { estados não participavam do custeio por } \\
\text { entenderem que outros componentes da rede são } \\
\text { sua prioridade. }\end{array}$ \\
\hline Gestão colegiada & $\begin{array}{l}8 \text { estados referiram comitê gestor estadual atuante } \\
\text { e } 12 \text { referiram grupo condutor estadual atuante. } \\
\text { Espaço de compartilhamento de informações e } \\
\text { resultados produzindo maior transparência. }\end{array}$ & $\begin{array}{l}\text { Coordenador que desconhecia as instâncias } \\
\text { gestoras previstas na legislação. } \\
\text { Percepção das decisões como sendo mais políticas } \\
\text { do que técnicas. }\end{array}$ \\
\hline Articulação regional & $\begin{array}{l}\text { Central de regulação conjunta entre Pernambuco } \\
\text { e Bahia (PEBA). Divisão dos atendimentos por tipo } \\
\text { de trauma. }\end{array}$ & $\begin{array}{c}\text { Municípios que não aderiam à regionalização. } \\
\text { Intervenção política e desestruturação dos acordos } \\
\text { na mudança de gestão. }\end{array}$ \\
\hline Informação para o planejamento & $\begin{array}{c}10 \text { estados recebiam indicadores que eram } \\
\text { utilizados para o planejamento. }\end{array}$ & $\begin{array}{l}5 \text { estados não funcionavam com sistemas } \\
\text { informatizados. } \\
4 \text { estados não produziam indicadores. }\end{array}$ \\
\hline $\begin{array}{l}\text { Desempenho estadual } \\
\text { diferenciado }\end{array}$ & $\begin{array}{l}\text { Atuação do Ministério Público na disponibilização } \\
\qquad \text { de leitos. } \\
\text { Enfermeiro na central para melhorar a relação com } \\
\qquad \text { o hospital. } \\
\text { Psiquiatra na equipe de regulacão. }\end{array}$ & $\begin{array}{c}\text { Fragilidade da função gestora dos estados na } \\
\text { definição numérica de ambulâncias com base nos } \\
\text { planos estaduais e regionais. }\end{array}$ \\
\hline
\end{tabular}

Fonte: entrevistas e painel de especialistas, elaboração própria.

Em outro estado, onde o SAMU é de responsabilidade municipal, ocorreu o oposto, o estado não participa do financiamento como previsto.

Com a transição para o modelo regionalizado, a implantação do SAMU passou a exigir planos estaduais e regionais de urgência, especificando suas necessidades. A compra de ambulâncias, centralizada no nível federal, com repasse para os estados, frequentemente ocorreu de forma não planejada, gerando problemas e ociosidade de recursos.

"Ambulância deve ser repassada quando estiver tudo estruturado. Chegam no município com 3 mil habitantes, como explicar pra população que aquela ambulância não pode ser utilizada porque as bases não estão prontas?" (E4).

"Correria das ambulâncias, algumas bases improvisadas" (E10).

A ingerência identificada se explica pela compra de ambulâncias desconsiderando a real necessidade numérica. A insuficiência de recursos municipais para custear a manutenção da frota acentuou esse problema.

"Em 2011, o ministério repassou 124 ambulâncias. Noventa e cinco estavam planejadas" (E4).

"Processo de implantação mais político do que técnico. Ministério joga ambulâncias no estado sem nenhum preparo" (E6).

"Em 2010, Brasília distribuiu ambulâncias para estados com afinidade política. Ficaram ambulâncias nos pátios” (E10).

"O município não tem como arcar. Os veículos rodam como ambulâncias sanitárias, fazendo remoção de pacientes” (E5).

Ficou evidente a fragilidade dos estados na definição das suas necessidades. Nesse contexto, o nível federal deixou de ser facilitador e funcionou como dificultador, com consequências para a capacidade de financiamento e para a afirmação do papel do estado na elaboração dos planos de saúde e gestão da regionalização.

"Somos uma esfera técnica cercada de decisões políticas. Temos que tornar os argumentos técnicos mais fortes que os politicos" (E11).

No que diz respeito à gestão colegiada, atualmente exige-se a constituição de grupos condutores estaduais e regionais. Na implantação do SAMU eram previstos os comitês gestores nacional, 
estaduais, regionais e municipais ${ }^{3}$. O nacional não chegou a ser efetivo 10 e os comitês de outros níveis foram implantados de forma diversa no país ${ }^{6,12}$. Segundo Portaria mais recente 2 , os grupos condutores não substituem os comitês gestores, apesar da sobreposição de atribuições, já que não compartilham de todos os membros. Os grupos condutores foram considerados mais potentes pela participação dos secretários de saúde. Entretanto, para os estados onde os comitês gestores eram mais atuantes, houve desestruturação de instância gestora existente.

Três estados não contam com qualquer instância gestora.

"Comitê gestor esquecido em 2012, grupo condutor ficou engavetado" (E6).

A existência desses instrumentos gestores implica negociações que privilegiam a regionalização e o planejamento, possibilitado com base nas informações geradas pelos serviços. A percepção predominante foi a de que os indicadores propostos pelas Portarias não são produzidos, e quando são não utilizam o planejamento. Ainda assim, coordenadores de dez estados planejam baseando-se em indicadores. Os documentos e relatórios acessados pela pesquisa confirmam que as poucas informações produzidas se restringem ao número de atendimentos, classificação em traumáticos, clínicos, obstétricos, pediátricos, psiquiátricos e tempo resposta.

Os coordenadores estaduais classificaram como potente sua capacidade frente aos municípios, apesar de desgastante pelas distâncias e pela troca de gestores. Entretanto, o seu papel é de mediação já que não podem interferir na autonomia federativa do município.

"Estado não tem poder de indução no município. É mediador, mostra o caminho" (E21).

Apesar das dificuldades, destaca-se a atuação dos estados de Pernambuco e Bahia, que em um acordo intitulado PEBA (Pernambuco/Bahia) compartilham recursos na região Petrolina e Juazeiro.

Apesar da dependência de recursos, demonstrou-se como a ação dos gestores foi primordial para o desenvolvimento das redes de urgência.

\section{Conclusão}

Ao longo dos poucos anos de implantação, o SAMU foi configurado como uma estratégia estruturante de atendimento às urgências no país. Sua implantação ocorreu quando a cobertura ESF ainda era insuficiente e não havia proposta para o enfretamento efetivo da carência de leitos. Portanto, ele cobriu um vazio assistencial, mas seu desempenho sofreu restrições.

Como não há definição normativa para municípios e estados sobre a sua atribuição no financiamento e prestação dos diversos serviços, estes entes federados produziram padrões diversos de responsabilização pelo SAMU, com destaque para os estados onde houve maior regionalização e municípios no início da implantação.

A diversidade do país em termos de infraestrutura de informação e comunicação e de serviços pré-existentes ora facilitou, ora dificultou a implantação dos SAMUs. O subfinanciamento foi evidenciado pela dificuldade em aumentar a frota de USA e de inovar na frota aérea e fluvial. Restrições estruturais atingiram mais o Norte e Nordeste.

A limitação relevante do estudo foi a ausência de indicadores de desempenho que dialogassem com o processo de implantação do SAMU. São necessários estudos de casos nos estados para elucidar processos locais. 


\section{Colaboradores}

G. O'Dwyer e M. T. Konder participaram da concepção do artigo, levantamento e análise dos dados, redação e revisão final. L. P. Reciputti e C. Macedo participaram do levantamento e análise dos dados, redação e revisão final do artigo. M. G. M. Lopes participou da análise dos dados, redação e revisão final do artigo.

\section{Agradecimentos}

Agradecemos aos financiadores, Ensp/Fiocruz (Inova ENSP 2013) e CNPq, e aos gestores estaduais entrevistados.

\section{Referências}

1. Machado CV, Salvador FGF, O’Dwyer G. O Serviço de Atendimento Móvel de Urgência no Brasil: uma análise da política nacional. Rev Saúde Pública 2011; 45:519-28.

2. Ministério da Saúde. Portaria no 1.600, de 7 de julho de 2011. Diário Oficial da União 2011; 8 jul.

3. Ministério da Saúde. Portaria no 1.864 , de 29 de setembro de 2003. Diário Oficial da União 2003; 6 out.

4. Wang HE, Mann NC, Carlson JN, Jacobson KE, Donnelly JP, Mueller LR. National characteristics of emergency medical services in frontier and remote areas. Prehosp Emerg Care 2016; 20:191-9.

5. Minayo MCS, Deslandes SF. Análise da implantação do sistema de atendimento pré-hospitalar móvel em cinco capitais brasileiras. Cad Saúde Pública 2008; 24:1877-86.

6. O'Dwyer G, Machado CV, Alves RP, Salvador FG. Atenção pré-hospitalar móvel às urgências: análise de implantação no Estado do Rio de Janeiro. Ciênc Saúde Coletiva 2016; 21:2189-200.

7. Lima DP, Leite MTS, Caldeira AP. Redes de atenção à saúde: a percepção dos médicos trabalhando em serviços de urgência. Saúde Debate 2015; 39:65-75.

8. Torres SFS, Belisário SA, Melo EM. A rede de urgência e emergência da macrorregião norte de Minas Gerais: um estudo de caso. Saúde Soc 2015; 24:361-73.

9. Cardoso RG, Francischini CF, Ribera JM, Vanzetto R, Fraga GP. Resgate aeromédico a traumatizados: experiência na região metropolitana de Campinas, Brasil. Rev Col Bras Cir 2014; 41:236-44.

10. O'Dwyer G, Mattos RA. O SAMU, a regulação no Estado do Rio de Janeiro e a integralidade segundo gestores dos três níveis de governo. Physis (Rio J.) 2012; 22:141-60.

11. Semensato G, Zimerman L, Rohde LE. Avaliação inicial do Serviço de Atendimento Móvel de Urgência na cidade de Porto Alegre. Arq Bras Cardiol 2011; 96:196-204.

12. Lima JC, Rivera FJU. Redes de conversação e coordenação de ações de saúde: estudo em um serviço móvel regional de atenção às urgências. Cad Saúde Pública 2010; 26:323-36.

13. Wang HE, Mann NC, Jacobson KE, Ms MD, Mears G, Smyrski K, et al. National characteristics of emergency medical services responses in the United States. Prehosp Emerg Care 2013; 17:8-14.

14. Cone DC, Irvine KA, Middleton PM. The methodology of the Australian Prehospital Outcomes Study of Longitudinal Epidemiology Project. Prehosp Emerg Care 2012; 16: 505-12.

15. Righi AW, Wachs P, Saurin TA. Characterizing complexity in socio-technical systems: a case study of a SAMU Medical Regulation Center. Work 2012; 41:1811-7. 
16. Nehme Z, Andrew E, Smith K. Factors influencing the timeliness of emergency medical service response to time critical emergencies. Prehosp Emerg Care 2016; 20:1-9.

17. Giddens A. A constituição da sociedade. 2a Ed. São Paulo: Martins Fontes; 1984.

18. Scheffer M, coordenador. Demografia médica no Brasil 2015. São Paulo: Departamento de Medicina Preventiva, Faculdade de Medicina, Universidade de São Paulo/Conselho Regional de Medicina do Estado de São Paulo/Conselho Federal de Medicina; 2015.

19. Seixas PHD, Silvestre DAMM, Viana ALD, Uchimura LYT, Pereira APCM. Movimentação médica no Brasil. http://www.resbr.net.br (acessado em Nov/2015).

\section{Abstract}

The Mobile Emergency Medical Service (SAMU) was the first component of the National Policy for Emergency Care implemented in Brazil in the early 2000. The article analyzed the implementation of mobile pre-hospital emergency care in Brazil. The methods included document analysis, interviews with state emergency care coordinators, and an expert panel. The theoretical reference was the strategic conduct analysis from Giddens' Structuration Theory. The results showed uneven implementation of the SAMU between states and regions of Brazil, identifying six patterns of implementation, considering the states' capacity to expand the population coverage and regionalize the service. Structural difficulties included physician retention, poorly equipped dispatch centers, and shortage of ambulances. The North and Northeast were the country's most heavily affected regions. $S A M U$ is formatted as a structuring strategy in the emergency care network, but its performance suffered the impact of limited participation by primary care in the emergency network and especially the lack of hospital beds.

Emergencies; Ambulances; Health Policy, Planning and Management
20. De Negri A, organizador. Cartografia do sistema hospitalar brasileiro (2005-2014). São Paulo: Hospital do Coração; 2014.

21. Ibanez N. Os hospitais e a rede de atenção às urgências e emergências: desafios. Consensus. Revista do Conselho Nacional de Secretários de Saúde 2013; III:36-43.

22. Bittencourt RJ, Hortale VA. Intervenções para solucionar a superlotação nos serviços de emergência hospitalar: uma revisão sistemática. Cad Saúde Pública 2009; 25:1439-54.

23. Ugá MAD, López EM. Os hospitais de pequeno porte e sua inserção no SUS. Ciênc Saúde Coletiva 2007; 12:915-28.

\section{Resumen}

El Servicio de Atención Móvil de Urgencia (SAMU) fue el primer componente de la Politica Nacional de Atención a las Urgencias, implantado en Brasil a inicio del año 2000. El artículo analizó el proceso de implantación de la urgencia pre-hospitalaria móvil en Brasil. Los métodos incluyeron un análisis documental, entrevistas con coordinadores estatales de urgencia y un panel de especialistas. Se utilizó el marco referencial teórico del análisis de la conducta estratégica de la Teoría de la Estructuración de Giddens. Los resultados evidenciaron una implantación del SAMU desigual entre estados y regiones, identificando seis patrones de implantación, considerándose la capacidad de los estados de expandir la cobertura poblacional $y$ de regionalizar. Las dificultades estructurales incluyeron la fijación de médicos, centrales de mal equipadas y escasez de ambulancias. Norte y Nordeste fueron las regiones más afectadas. El SAMU está configurado como estrategia estructurante de la red de urgencias, pero su desempeño sufrió el impacto de la poca participación de la atención primaria en la red de urgencias $y$, principalmente, de la falta de camas en hospitales.

Urgencias Médicas; Ambulancias; Políticas, Planificación y Administración en Salud
Recebido em 18/Mar/2016

Versão final reapresentada em 11/Set/2016

Aprovado em 22/Set/2016 